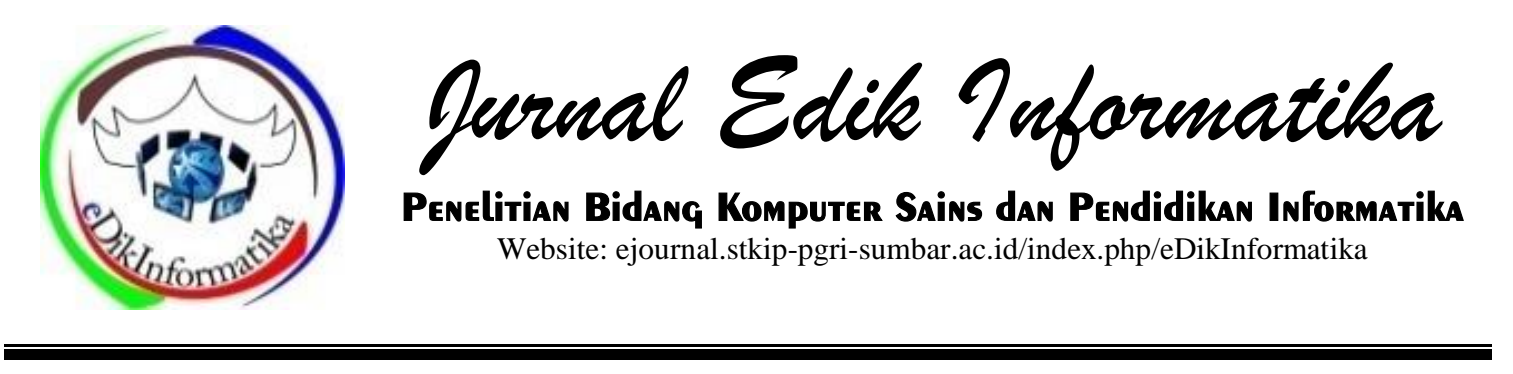

\title{
APPLICATION OF THE SECURE HASHING ALGORITHM (SHA) METHOD AND ROLE-BASED ACCESS SECURITY AUTHENTICATION IN LARAVEL 7
}

\author{
Thomson Mary ${ }^{1}$, Anggri Yulio Pernanda ${ }^{2}$, Satrio Junaidi ${ }^{3}$ \\ ${ }^{1,2,3}$ STKIP PGRI Sumatera Barat \\ thomsonmary1980@gmail.com
}

INFO ARTIKEL

Diterima:

19 Mei 2021

Direview:

21 Mei 2021

Disetujui:

16 Juni 2021

Kata Kunci:

Framework Laravel,

Secure Hashing

Algorithm,

Authentication,

Middleware, $S Q L$

injection

\begin{abstract}
The purpose of this research is to fix the weakness of Laravel's default login system and develop it with a better login system by using algorithmic methods which are also the result of the research. The system development method is a combination of several methods, namely: Secure Hashing Algorithm (SHA), Multi Level Access Algorithm (MLA) and Middleware Checking Access System. Testing is done by Black Box Testing where the login system modified from the Laravel framework is in the form of a Secure Hashing Algorithm (SHA) algorithm using a 256 bit SHA-3 algorithm to test it with SQL Injection, Multi Level Access Algorithm (MLA) by adding a login controller algorithm, kernel and security access on the dashboard admin content and homepage content and the Middleware Checking Access System which was tested with illegal access from the administrator link. The test results show success that can be developed in the next research
\end{abstract}

\section{PENDAHULUAN}

Laravel merupakan aplikasi pengembangan website yang menggunakan bahasa pemrograman PHP dimana laravel memiliki arsitektur MVC (Model View Controller) yang sangat dinamis dan disukai web developer pada saat ini ditinjau dari banyak kelebihannya. Pada era revolusi industri 4.0 dan revolusi industri 5.0, laravel merupakan sebagian sistem informasi yang mampu untuk diterapkan secara luas, dinamis, mudah serta sederhana untuk aplikasi berbasis web maupun sebagai end user untuk aplikasi berbasis mobile dari skala kecil hingga besar dari perusahaan-perusahaan.
Keunggulan lain dari sistem login pada framework Laravel dari segi pengolahan data seperti : performance lebih cepat, reload data lebih stabil, memiliki keamanan data, menggunakan fitur canggih seperti blade yang menggunakan konsep HMVC (Hierarchical Model View Controller), tersedianya banyak library yang sudah siap untuk digunakan dan adanya fitur pengelolaan migrations untuk pembuatan skema table pada database (Handika \& Purbasari, 2018) yang semua kelengkapan tersebut bisa dimanfaatkan dalam sistem login framework Laravel. 
Kelebihan MVC dapat dilihat dari sumber berikut The concept of $M V C$ makes the program structured by separating logical into 3 parts, namely model, view and controller. Like the framework in general, Laravel also uses the MVC structure, therefore Laravel can easily manage databases such as input data to the database, update data and manage other data.(Santoso et al., 2021). Sistem login yang dipersembahkan oleh framework Laravel khususnya pada Laravel 7, telah sesuai dengan alokasi kebutuhannya, sehingga untuk sistem login Laravel 7 tidak memerlukan lagi tambahan dalam bentuk scripting, dalam penelitian ini disebut sebagai default system.

Penggunaan login authentication merupakan sistem bawaan pada Laravel 7 telah sesuai sebagai operasi standarnya, ternyata akan terkendala dalam mengakses sistem yang membutuhkan banyak pengguna yang disebut dengan Multi Level Access (MLA). MLA dibutuhkan jika sebuah sistem memerlukan lebih dari leveladministrator yang mengaksesnya, seperti leveluser-user di bawahnya dengan akses yang terbatas, kendala tersebut akan berlanjut tidak hanya dalam level akses belaka akan tetapi juga dalam kewenangan halaman sistem yang saling tumpang tindih. Hal ini akan berdampak rusaknya operasional yang membutuhkan hirarki dalam sebuah sistem Multi Level Access (MLA).

Perubahan pada default system untuk login ini dirasa menyulitkan untuk pengembangan sistem informasi ke depannya, hal ini dikarenakan terbatasnya kemampuan dan sumber daya dalam memodifikasi skrip Laravel yang bukan dari defaultsystem, dimana kemampuan dan sumber daya dimaksud mesti sering dilakukan dalam penelitianpenelitian yang komprehensif serta berkesinambungan. Untuk saat ini kemampuan dan sumber dayasecara dasar-dasarnya bagi programmer Laravel disediakan di website www.laravel.com. Seharusnya untuk pengembangan-pengembangan sistem informasi ke depannya yang diperbaharui, agar pembaharuan yang terjadi tidak begitu signifikan merusak tatanan sistem informasi yang telah ada, untuk itulah diperlukan sistem akses yang baru yang mampu untuk ditambahkan tanpa merusak default system yang akan memperbaiki operasional secara lebih sempurna.

Algoritma Secure Hash Standard (SHS) menspesifikasikan SHA-1 untuk menghitung nilai hash dari sebuah pesan atau file SHA-1 memiliki panjang pesan maksimal 264 bits dan memiliki keluaran sebesar 160 bits yang dinamakan messagedigest atau hashcode. Message digest tersebut dapat digunakansebagai masukan untuk Digital Signature Algorithm (DSA), yang digunakan untuk menghasilkan signature untuk memverifikasi pesan tersebut.(Kurniawan et al., 2017).

\section{METODE}

Cara sistematis yang dilakukan dalam penyelesaian masalah pada penelitian ini sekaligus tahapan pengujian yang dilakukan dalam penelitian digambarkan dalam tahapantahapan diperlihatkan pada gambar 1 .

Dalam gambar 1, dijelaskan per bagian blok metode penelitian yang merupakan skema penelitian seperti berikut:

1. Studi Literatur.

Studi Literatur dalam topik Secure Hashing Algorithm (SHA) Method And Role-Based Access Security Authentication In Laravel 7 ini diambil dalam jurnal-jurnal tentang SHA dan Role Based System. 


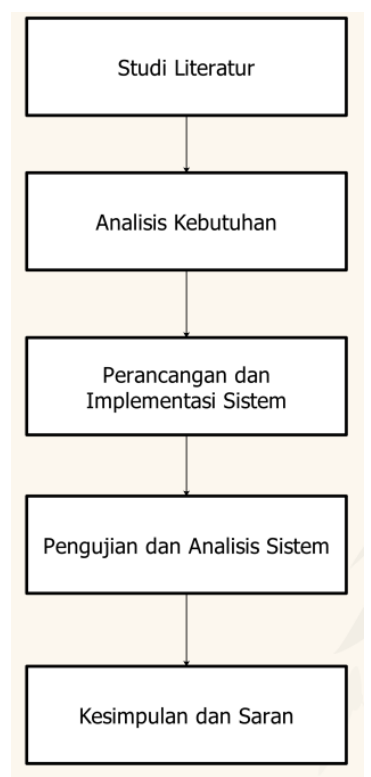

Gambar 1. Diagram Metode Penelitian yang Direncanakan (Kurniawan et al., 2017)

dalam akses keamanan berbasis skrip. Adapun jurnal penelitian yang relevan untuk ini adalah jurnal yang memuat topik tentang: sistem keamanan website, sistem basis data, algoritma keamanan data dan struktur data. Adapun literatur khusus yaitu literatur yang membahas khusus tentang topik ini seperti : Laravel, algoritma SHA, algoritma Rijndael dan algoritma Honeypot. Jurnal tersebut pembahasannya seperti berikut ini :

a. Algoritma Secure Hash Standard (SHS) menspesifikasikan SHA-1 untuk menghitung nilai hash dari sebuah pesan atau file SHA-1 memiliki panjang pesan maksimal 264 bits dan memiliki keluaran sebesar 160 bits yang dinamakan messagedigest atau hashcode.

Messagedigesttersebut dapat digunakansebagai masukan untuk Digital Signature Algorithm (DSA), yang digunakan untuk menghasilkan signature untuk memverifikasi pesan tersebut.(Kurniawan et al., 2017)

b. Honeypot merupakan sebuah sistem atau komputer yang sengaja "dikorbankan" untuk menjadi target serangan dari hacker. Komputer tersebut melayani setiap serangan yang dilakukan oleh hacker. Metode ini ditujukan agar administrator dari server yang akan diserang dapat mengetahui trik penetrasi yang dilakukan hacker serta bisa melakukan antisipasi dalam melindungi server yang sesungguhnya (Setiawan et al., 2013)

c. Rijndael termasuk dalam jenis algoritma kriptografi yang 
sifatnya simetri dan blok sandi. Dengan demikian algoritma ini mempergunakan kunci yang sama saat enkripsi (bentuk acak) dan dekripsi (mengembalikan ke bentuk semula) serta masukan dan keluarannya berupa blok dengan jumlah bit tertentu. (Dharmawan et al., 2013)

2. Analisis Kebutuhan. Analisis kebutuhan disusun berdasarkan permasalahan yang ada dalam sistem login default system Laravel 7 dan dikembangkan sebuah solusi untuk membuat sistem login lebih sempurna. Analisis kebutuhan ada pada penggunaan Secure Hashing Algorithm (SHA) dan Algoritma Role-Based Access Security Authentication untuk keamanan data dan akses serta hasil dan ujicoba yang sesuai dengan kebutuhan yang diinginkan.

3. Perancangan dan Implementasi Sistem. Dirancang dengan menggunakan algoritma Secure Hashing Algorithm (SHA) Method dan sitem Role-Based Access Security Authentication serta diimplementasikan dalam bahasa pemrograman PHP yang ada dalam framework Laravel 7 sehingga menciptakan sistem login yang baru dan lebih sempurna untuk penerapan dalam sistem informasi berbasiskan Multi Level Access (MLA).

4. Pengujian dan Analisis Sistem. Pengujian dilakukan sesuai dengan prosedur pengujian Black Box Testing yang akan menguji validitas sistem dan keamanan sistem yang baru.

5. Kesimpulan dan Saran. Kesimpulan dari penelitian serta saran-saran untuk penelitian selanjutnya yang lebih disempurnakan.

Berikut bentuk kerja default system login dalam Laravel 7 yang telah dianalisa dari perancangan login laravel dalam website resmi www.laravel.com disediakan sebagai bawaan dari framework tersebut. Berikut analisa yang dilakukan dari penelitian ini berdasarkan instalasi Laravel Login secara default system dikumpulkan dari vendor resmi laravel yaitu www.laravel.com dimana disana diperlihatkan tata cara membuat System Login secara default. Hasil dari analisa sistem yang diperlihatkan pada gambar 2.

Dalam gambar 2, diperlihatkan terdapat 3 (tiga) blok utama dalam sistem yaitu Secure Hashing Algorithm (SHA), Middleware Checking Access System, Content Management System. Default System ini juga memiliki fasilitas seperti diperlihatkan oleh tabel 1.

Di dalam default system belum terdapat solusi yang ditawarkan untuk memecahkan beberapa persoalan yang telah dijelaskan pada pendahuluan di atas. Masalah itu diusulkan untuk menambahkan algoritma-algoritma penunjang untuk sistem yang mampu memberikan solusi dalam hal akses sistem yang majemuk atau disebut dengan Multi Level Access (MLA).

$$
\text { Multi Level Access (MLA) }
$$
menawarkan sistem kerja tambahan yang diharapkan mampu dalam memproses user dengan berbagai tingkatan level akses pada sistem. MLA juga diharapkan tidak hanya sebatas akses, akan tetapi juga keamanan optimal untuk mengakses halamanhalaman yang terbatas / forbidden access melalui link-link langsung untuk jenis level akses tertentu. 


\section{Flowchart Kerja Default System Login Laravel 7}

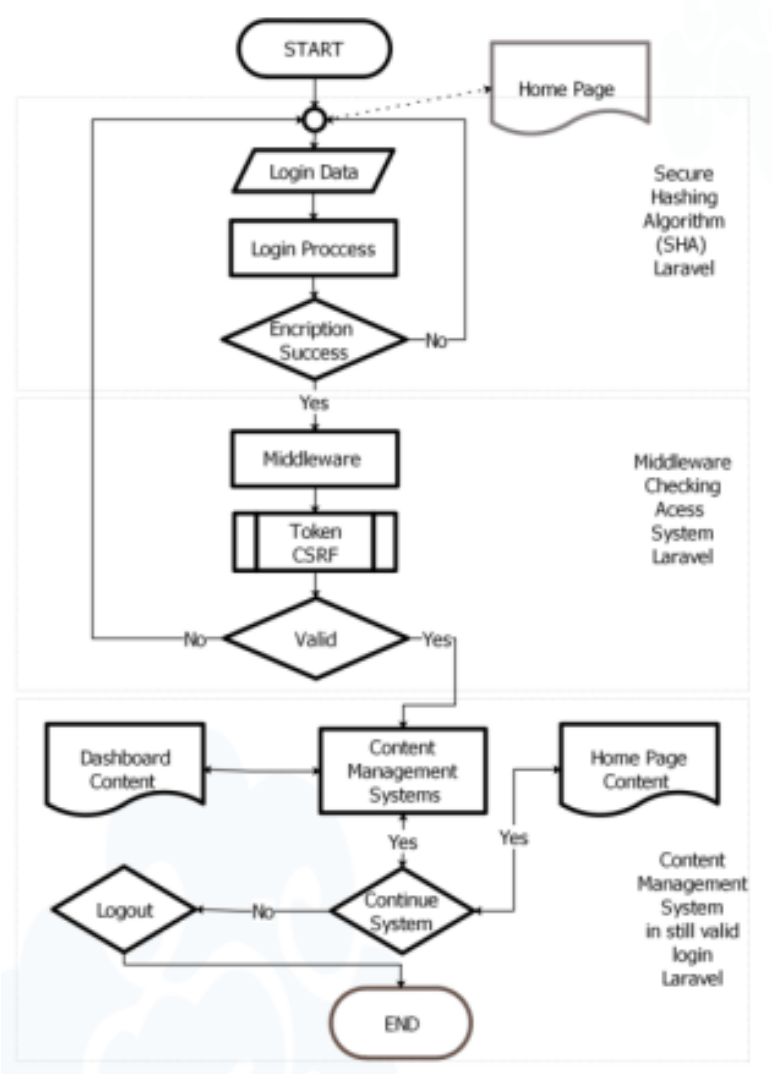

Gambar 2. Kerja Default System Login Laravel 7

Sumber : Pengembangan Hasil Penelitian dari www.laravel.com website resmi Laravel

Tabel 1. Tabel Hasil Analisis Kelengkapan Default System LoginLaravel. Hasil dari Analisis Sistem Setelah Instalasi Laravel System Login Default

\begin{tabular}{clc}
\hline No & \multicolumn{1}{c}{ Items } & Availability \\
\hline 1. & Packages laravel/ui (login, register \& logout) & yes \\
2. & Laravel ui boostrap auth & yes \\
3. & Node Package Manager $(N P M)$ & yes \\
4. & Middleware & yes \\
5. & Authentication & yes \\
6. & Dashboard Content & yes \\
7. & Homepage Content & yes \\
8. & Enable boostrap template application & yes \\
9. & Migration table & yes \\
10. & Content Management System & yes \\
& & \\
\hline
\end{tabular}


Multi Level Access (MLA) dibuat dengan Role-Based Access Security Authentication, memodifikasi algoritmaalgoritma yang diperlukan untuk mampu diterapkan dalam menyelesaikan persoalan ini.

\section{HASIL DAN PEMBAHASAN}

Berikut ini sistem kerja hasil dari penelitian yang dirancangan dalam sistem Multi Level Access (MLA) melalui penggunaan algoritma RoleBased Access Security Authentication. Hasil analisis penelitian diuraikan seperti gambar 3.

Pada gambar 3 diperlihatkan sistem Multi Level Access (MLA) dengan adanya can:manage, yang merupakan bagian algoritma dari Role-Based Access Security Authentication dimana setiap login yang berhasil valid akan memasuki tahapan based role authentication untuk memastikan si logger ini masuk dalam level yang telah divalidasikan. Level tersebut terdapat 3 (tiga) bagian yaitu : admin, author dan user. Multi Level Access (MLA) System juga mampu memilah dan memilih halaman dashboard mana yang mesti mereka masuki sehingga halaman-halaman yang private untuk level di atasnya tidak akan mampu dimasuki, dan jika masuk dengan paksaan yaitu dengan cara memasuki langsung link yang diketahui untuk administratornya maka sistem authentication based role akan mengarahkannya ke halaman error untuk tidak dapat mengakses sistem, hal ini sebagai perlindungan keamanan tambahan yang diusulkan dalam penelitian ini.

Pada Tabel 2 diperlihatkan sistem yang diusulkan dengan items tambahan pada point 11-14 yaitu: Multi Level Access (MLA), Role-Based Access Security Authentication, Can:manage Algorithm, Forbidden Access Page and
Forced Out yang merupakan usulan perbaikan sistem login yang diharapkan mampu untuk menanggulangi masalah yang terdapat dalam default system.

Kelengkapan tambahan pada sistem yang baru adalah sebagai berikut :

1. Perancangan Algoritma Secure Hashing Algorithm (SHA), yaitu perancangan algoritma dengan menggunakan SHA-3 256 bit. Ukuran output yang dihasilkan oleh algoritma SHA-1 berukuran 160 bits. Sedangkan ukuran output yang dihasilkan SHA-3 berukuran beragam, mulai dari 224, 256, 384, dan 512 bits. Menjadikan algoritma SHA-3 lebih tahan terhadap serangan brute force (Kurniawan et al., 2017). Selanjutnya algoritma yang dibuat disini yaitu : Checking Auth with provider, Confirm Password Controller, Register Controller, Verification Controller.

2. Perancangan Algoritma Middleware Checking Access System, yaitu perancangan algoritma yang meliputi algoritma: Authentication, Checkrole, Verify Csrf Token

3. Perancangan Algoritma Multi Level Access System, yaitu perancangan algoritma yang meliputi : Login Controller, Kernel

4. Perancangan Content Management System yaitu algoritma yang meliputi Home Page Content (Template Home CMS)dan Dashboard Content (Dashboard Admin, Dashboard Author, Dashboard User)

5. Hasil dan Pembahasan Sistem Login yang Diusulkan

Dalam perancangan sistem, terlebih dahulu diciptakan database untuk login dan diisi dengan cara register di sistem, Seperti pada gambar 4. 
Flowchart Kerja Sistem

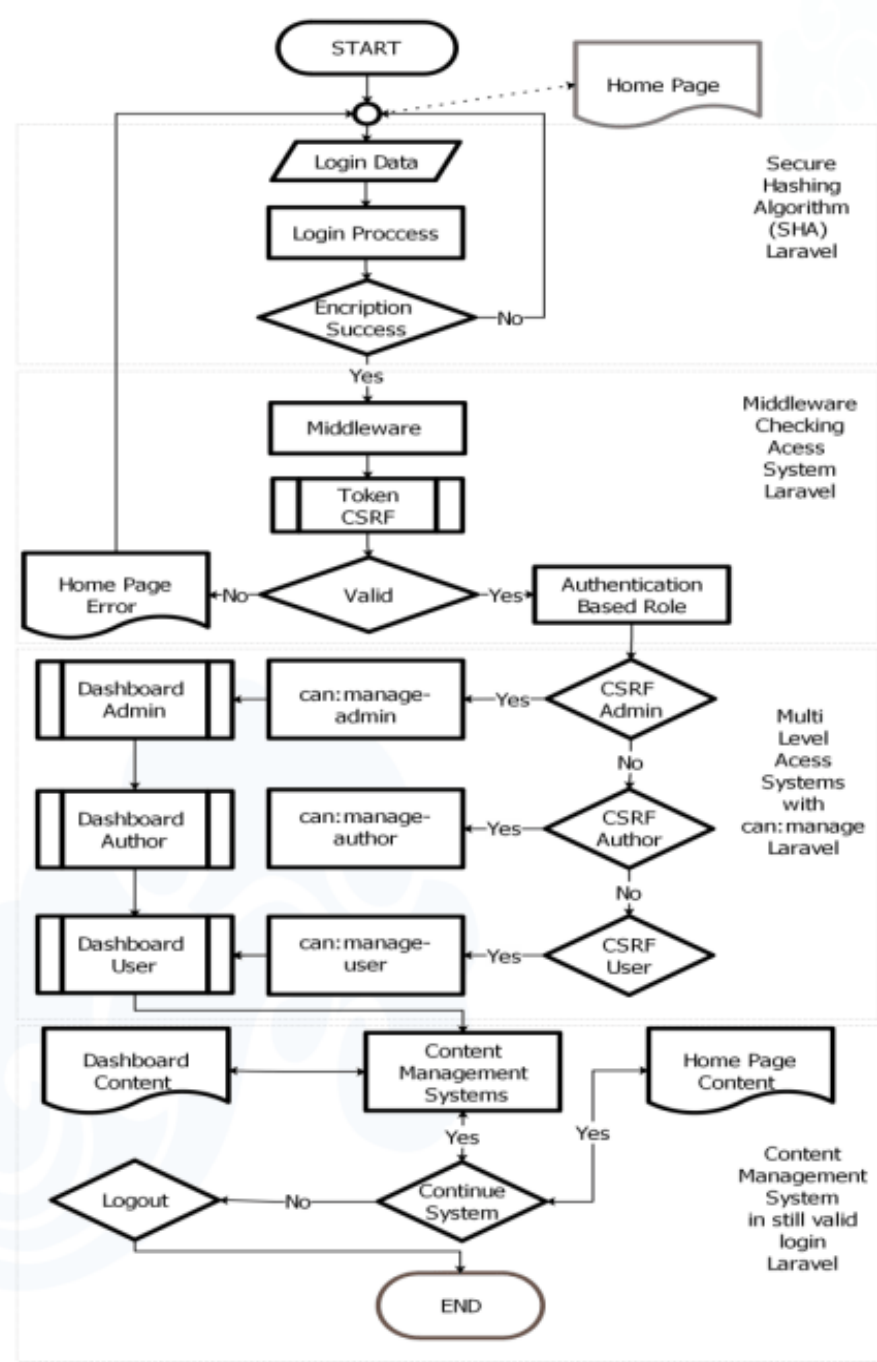

Gambar 3. Kerja Sistem Login yang Baru dengan Multi Level Access (MLA) \& Role-Based Access Security Authentication Laravel Hasil dari Analisis Penelitian

Tabel 2. Tabel Hasil Analisis Pembahasan Kelengkapan Sistem yang Baru

\begin{tabular}{clc}
\hline No & \multicolumn{1}{c}{ Items } & Availability \\
\hline 1. & Packages Laravel/ui (Login, Register \& Logout) & yes \\
2. & Laravel ui Boostrap Auth & yes \\
3. & Node Package Manager (NPM) & yes \\
4. & Middleware & yes \\
5. & Authentication & yes \\
6. & Dashboard Content & yes \\
7. & Homepage Content & yes \\
8. & Enable Boostrap Template Application & yes \\
9. & Migration Table & yes \\
10. & Content Management System & yes
\end{tabular}


11. Multi Level Access (MLA) yes

12. Middleware Checking Access System yes

13. Can:manage Algorithm yes

14. Forbidden Access Page and Forced Out yes

\begin{tabular}{|c|c|c|c|c|c|c|c|c|}
\hline & $\#$ & Name & Type & Collation & Attributes & Null & Default Comments & Extra \\
\hline$\square$ & 1 & id $P$ & bigint(20) & & UNSIGNED & No & None & AUTO_INCREMENT \\
\hline$\square$ & 2 & name & $\operatorname{varchar}(255)$ & utf8mb4_unicode_ci & & No & None & \\
\hline$\square$ & 3 & email $\gg$ & $\operatorname{varchar}(255)$ & utf8mb4_unicode_ci & & No & None & \\
\hline$\square$ & 4 & email_verified_at & timestamp & & & Yes & NULL & \\
\hline$\square$ & 5 & password & $\operatorname{varchar}(255)$ & utf8mb4_unicode_ci & & No & None & \\
\hline$\square$ & 6 & avatar & $\operatorname{varchar}(255)$ & utf8mb4_unicode_ci & & Yes & NULL & \\
\hline$\square$ & 7 & remember_token & $\operatorname{varchar}(100)$ & utf8mb4_unicode_ci & & Yes & NULL & \\
\hline$\square$ & 8 & created_at & timestamp & & & Yes & NULL & \\
\hline 回 & 9 & updated_at & timestamp & & & Yes & NULL & \\
\hline
\end{tabular}

Gambar 4. Struktur Table Pengguna dari Database

\section{Perancangan Algoritma Secure Hashing Algorithm (SHA) \\ Algoritma Checking Auth with} provider. Algoritma ini bertujuan untuk menciptakan hak akses dari database berupa admin, author dan user yang diperbolehkan dalam mengakses sistem agar hak akses tersebut masuk dan dicek terlebih dahulu. Diberikan seperti berikut

$$
\begin{aligned}
& <? p h p \\
& \text { return [ } \\
& \text { 'admin' => [ } \\
& \text { 'driver' => 'session', } \\
& \text { 'provider' => 'admin', ], } \\
& \text { 'apiadminin' => [ } \\
& \text { 'driver' => 'token', } \\
& \text { 'provider' => 'admin', ], } \\
& \text { 'author' => [ } \\
& \text { 'driver' => 'session', } \\
& \text { 'provider' => 'author', ], } \\
& \text { 'apiauthor' => [ } \\
& \text { 'driver' => 'token', } \\
& \text { 'provider' => 'author', ], } \\
& \text { 'user' => [ } \\
& \text { 'driver' => 'session', }
\end{aligned}
$$

$$
\begin{gathered}
\text { 'provider' => 'user', ], } \\
\text { 'apiuser' => [ } \\
\text { 'driver' => 'token', } \\
\text { 'provider' => 'user', ], ], } \\
\text { 'providers' }=>\text { [ } \\
\text { 'users' }=>\text { [ } \\
\text { 'driver' }=>\text { 'eloquent', } \\
\text { 'model' }=>\text { App } \backslash \text { User::.class, }
\end{gathered}
$$

],

$$
\begin{aligned}
\text { 'admin' } & => \\
\text { 'driver' } & =>\text { 'eloquent', } \\
\text { 'model' } & =>\text { App } \backslash \text { User::class, }
\end{aligned}
$$

],

], ],

$$
\begin{aligned}
\text { 'author' } & => \\
\text { 'driver' } & =>\text { 'eloquent', } \\
\text { 'model' } & =>\text { App } \backslash \text { User::class, }
\end{aligned}
$$$$
\text { 'passwords' }=>\text { [ }
$$$$
\text { 'users' }=>\text { [ }
$$$$
\text { 'provider' => 'users', }
$$$$
\text { 'table' => }
$$

'password_resets',

$$
\begin{aligned}
& \text { 'expire' }=>60, \\
& \text { 'throttle' }=>60, \quad], \quad],
\end{aligned}
$$$$
\text { 'password_timeout' }=>10800,] \text {; }
$$ 
Algoritma Confirm Password Controller. Algoritma ini bertujuan untuk menciptakan setiap halaman yang ingin diberikan hak akses agar nantinya cukup dengan memberi perintah "auth" maka halaman tersebut tidak akan bisa diakses kecuali hanya dengan login, diberikan sebagai berikut :

$$
\begin{aligned}
& <\text { ?php } \\
& \text { namespace }
\end{aligned}
$$

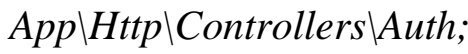

use

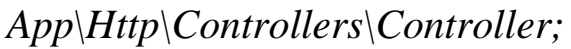
use

App \Providers $\backslash$ RouteServiceProvider; use

Illuminate $\backslash$ Foundation $\backslash$ Auth $\backslash$ ConfirmsP asswords;

class ConfirmPasswordController extends Controller

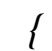

$/ *$

$$
1-
$$

| Confirm Password Controller

II This controller is responsible for handling password confirmations and

| uses a simple trait to include the behavior. You're free to explore | this trait and override any functions that require customization.

*/

use ConfirmsPasswords;

protected \$redirectTo=

RouteServiceProvider::HOME;

public function __construct()

i

\$this->middleware('auth'); \}

\}

Algoritma Verification Controller. Algoritma ini bertujuan untuk meneruskan verifikasi email dari algoritma confirm password controllerdengan beberapa pilihan verifikasi yaitu melanjutkan, masuk ke halaman yang telah diverifikasi atau keluar dari sistem. Diberikan sebagai berikut :

$$
\begin{aligned}
& <\text { ?php } \\
& \text { namespace }
\end{aligned}
$$

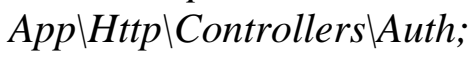

use

App $\backslash$ Http $\backslash$ Controllers $\backslash$ Controller;

use

App $\backslash$ Providers $\backslash$ RouteServiceProvider; use

Illuminate $\backslash$ Foundation $\backslash$ Auth $\backslash$ VerifiesEm ails;

class VerificationController extends Controller \{

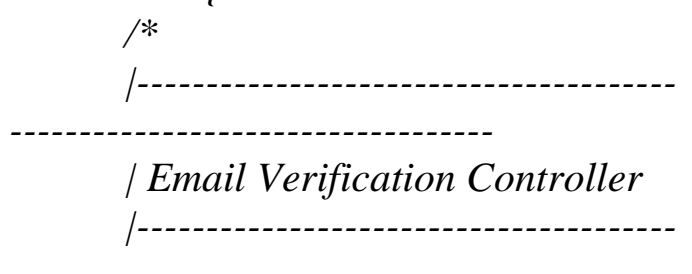

I| This controller is responsible for handling email verification for any | user that recently registered with the application. Emails may also

I be re-sent if the user didn't receive the original email message.

*/

use VerifiesEmails;

/**

* Where to redirect users after verification.

* @var string

*/

protected \$redirectTo= RouteServiceProvider::HOME; /**

* Create a new controller instance.

*@return void

*/

public function _ construct()

\$this->middleware('auth');

\$this->middleware('signed')-

$>$ only('verify'); 
\$this-

$>$ middleware ('throttle:6,1')-

>only('verify', 'resend'); \} \}
Tujuan algoritma ini untuk register terhadap nama, email dan password yang akan digunakan login ke dalam sistem. Khusus untuk password dibuat dengan algoritma hash dimana password akan di-encode ke dalam digit SHA-3 256 bit tanpa memperdulikan berapa karakter inputnya dan disimpan dalam tabel di database. Bentuk Algoritma untuk register dan login ditampilkan pada gambar 5 dan gambar 6 memperlihatkan diagram alur kerja Register dan Login.

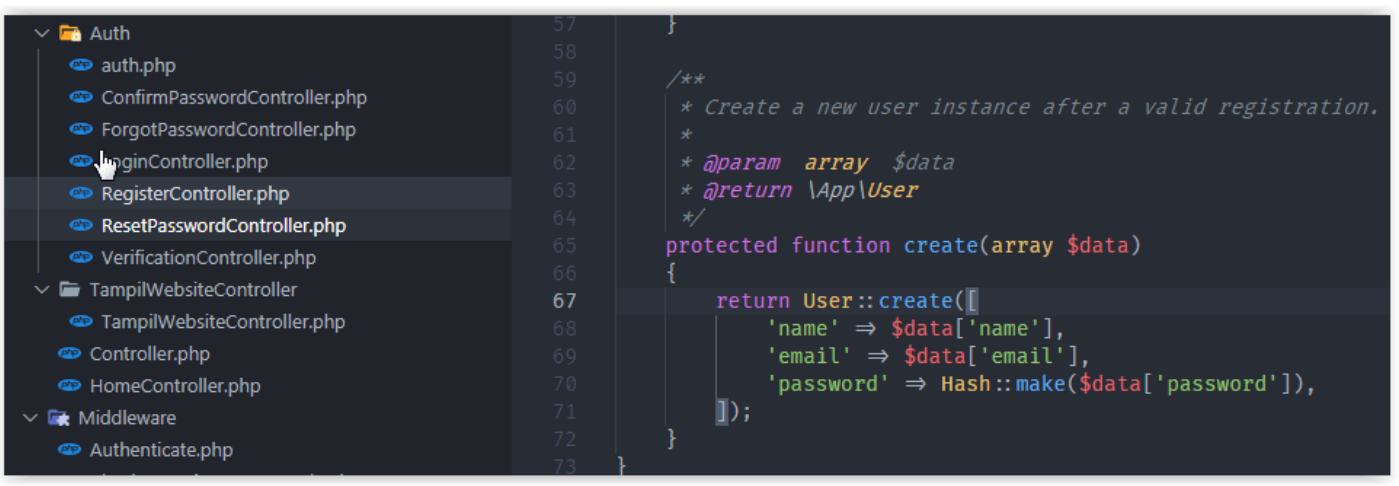

Gambar 5. Algoritma Create untuk Register

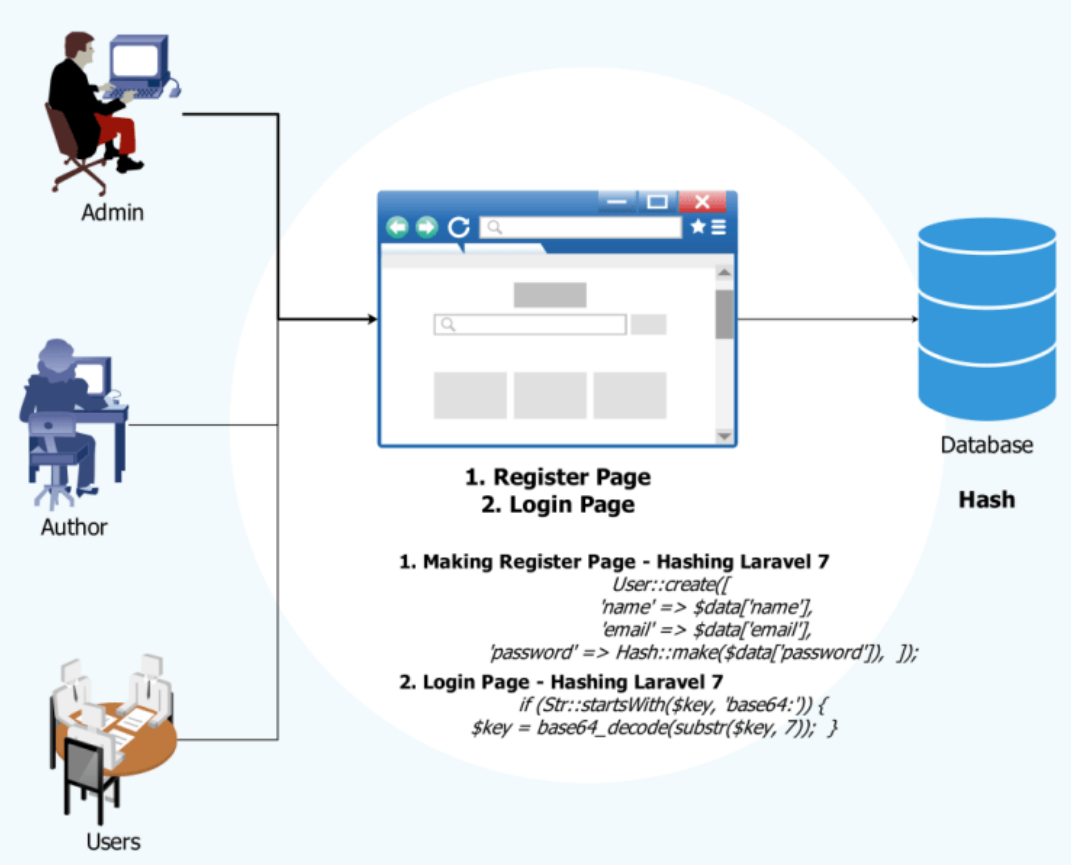

Gambar 6. Diagram Alur Kerja Register dan Login dengan Hash (SHA-3) 256 bit 


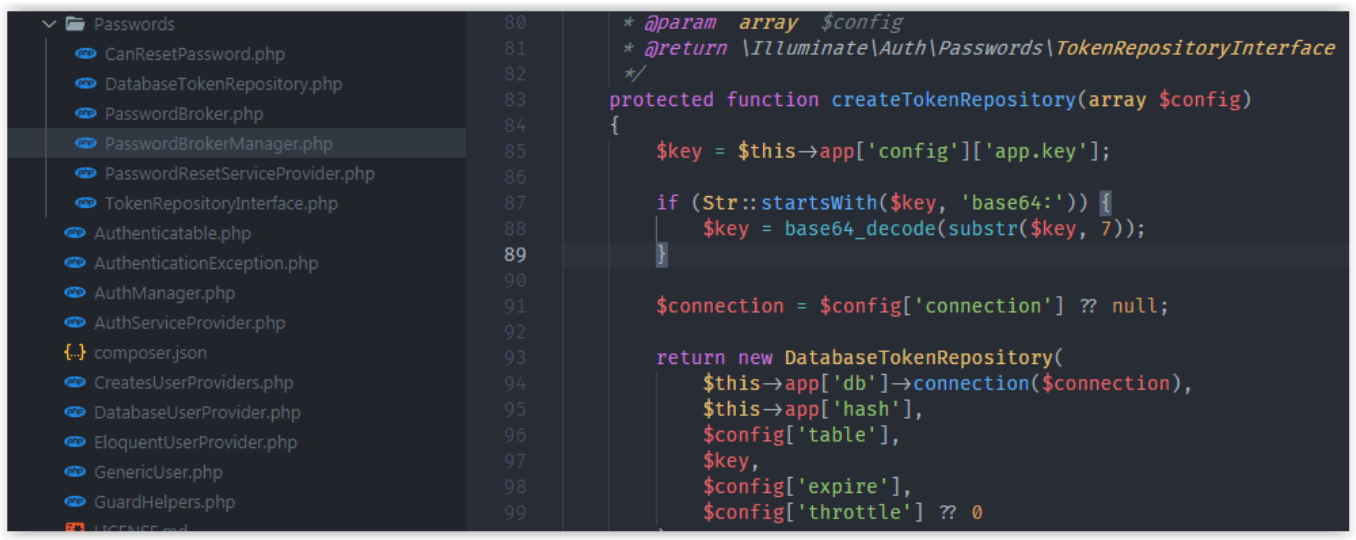

Gambar 7. Decode. Membaca Hashing dari Database

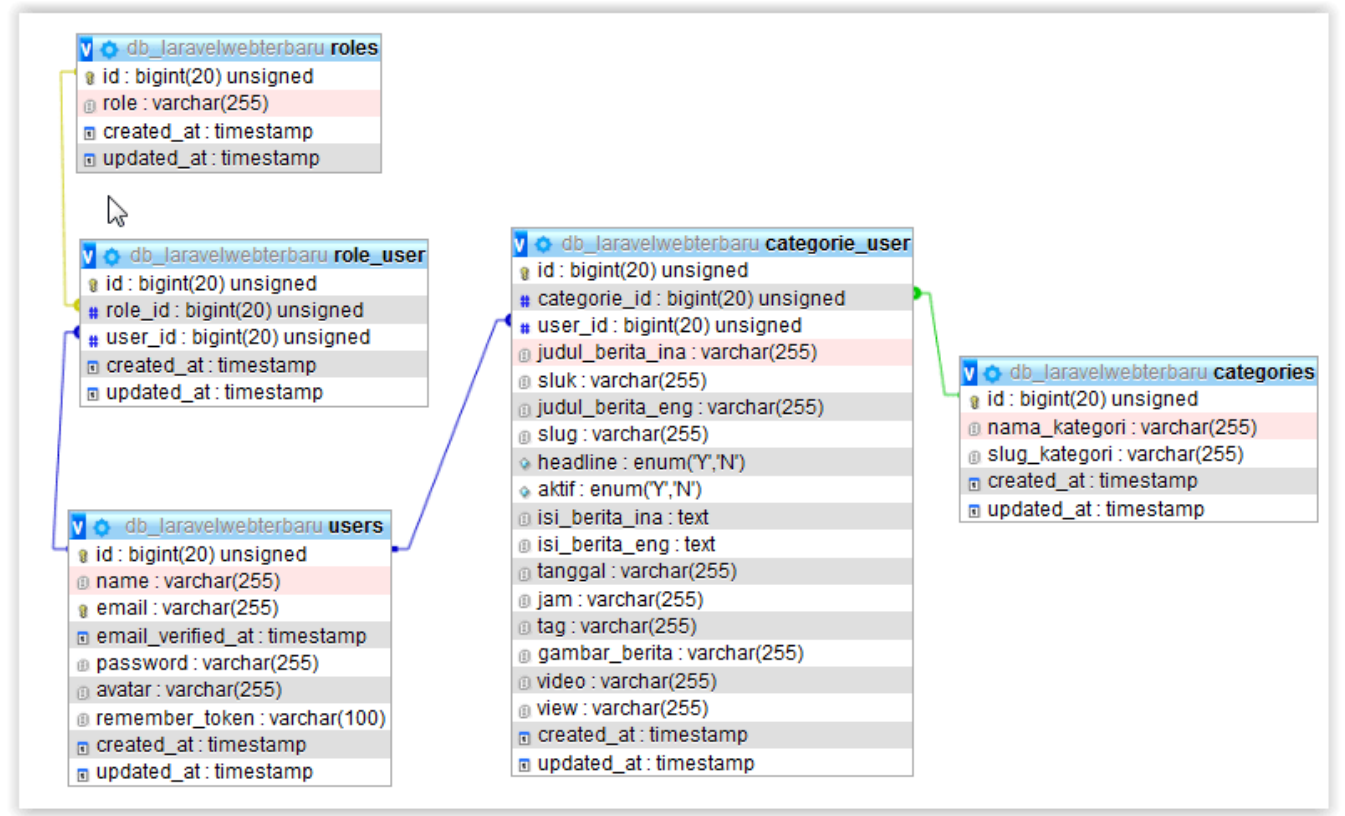

Gambar 8. Rancangan Entity Relationship Diagram database yang diusulkan

Proses mengembalikan data yang telah di-encode dan tersimpan dalam database tersebut maka dari itu diperlukan decode yang akan mengembalikan kembali ke dalam bentuk text yang diambil dari database. Berikut Algoritmanya :

$$
\begin{aligned}
& \text { if } \quad(\text { Str::startsWith(\$key, } \\
& \text { 'base64:')) } \\
& \text { \$key= } \\
& \text { base64_decode(substr(\$key, 7)); \} }
\end{aligned}
$$

Gambar 7 memperlihatkan decode hashing dari database dan database dirancang sebagaimana seperti yang terlihat pada gambar 8. Dari gambar 8 dapat disimpulkan bahwa tabel-tabel dirancang sesuai dengan MultiLevelAccess (MLA) dimana disana ditambahkan tabel role yang isinya adalah admin, author dan user yang terkoneksi dengan tabel user itu sendiri. Sehingga untuk mengakses sistem, data dari tabel role inilah yang dibaca oleh algoritma MLA

\section{Perancangan Algoritma Middleware Checking Access System \\ Algoritma Authentication.}

Algoritma ini bertujuan untuk membuat 
halaman default untuk login dengan nama "login", dan sekalian mengarahkan ke halaman ini jika terdapat session yang sudah kadaluarsa. Diberikan sebagai berikut:

$<$ ?php

namespace App $\backslash$ Http $\backslash$ Middleware; use

Illuminate $\backslash$ Auth\Middleware $\backslash$ Authentica te as Middleware;

class Authenticate extends Middleware \{

$/ * *$

* Get the path the user should be redirected to when they are not authenticated.

Vlluminate $\backslash H t t p \backslash$ Request \$request

@param

*@return string|null

*/

protected function

redirectTo(\$request) i

if ( \$request-> expectsJson()) \{ return route('login'); $\quad\}\}$

Algoritma Checkrole. Algoritma ini memberikan klarifikasi terhadap akses yang sesuai dengan role yang diizinkan. Jika user biasa mengakses halaman dari author atau author mengakses link dari admin maka "forbidden access" mengunci dihalaman error untuk kembali diarahkan ke halaman akses yang benar dan diakui dari sistem saja. Diberikan sebagai berikut :

$<$ ?php

namespace App \Http\Middleware;

use Closure;

class checkRole

i

$$
/ * *
$$

* Handle an incoming request.

$$
\text { * @param }
$$

Vlluminate $\backslash$ Http $\backslash$ Request \$request

* @param \Closure \$next

*@return mixed

*/ public function handle(\$request, Closure \$next,...\$roles) ( if (in_array(\$request->user()$>$ role, \$roles)) \{ return \$next(\$request); \} return redirect('Forbiden

Access!'); \} \}

Algoritma Verify Csrf Token. Algortima ini memberikan pilihan jika setelah si login berhasil masuk sistem apakah link halaman tersebut disertai dalam akses atau tidak, jika tidak ada link halaman yang mesti ikut dalam akses maka dikosongkan saja.

$$
<\text { ?php }
$$

namespace App $\backslash$ Http\Middleware; use

Illuminate $\backslash$ Foundation $\backslash H t t p \backslash$ Middlewar e $\backslash$ VerifyCsrfToken as Middleware; class VerifyCsrfToken extends Middleware \{ $/ * *$

* The URIs that should be excluded from CSRF verification.

*@var array

*/

protected \$except $=[$

//

]; $\}$

Perancangan Algoritma Multi Level Access System.

Algoritma

Login

Controller.Algoritma ini bertujuan untuk membuat polarisasi terhadap akses level yang akan masuk ke dashboard content atau home content. Disini juga diperlihatkan pengamanan yang berlapis tidak hanya login email dan password saja akan tetapi hak aksesnya juga langsung terpolasisasi agar sesuai aksesnya dengan yang diinginkan sistem. Diberikan sebagai berikut:

$<? p h p$

namespace

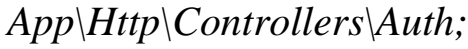

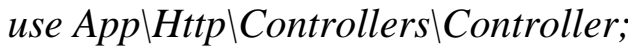


use

App $\backslash$ Providers $\backslash$ RouteServiceProvider ;

use

Illuminate Foundation $\backslash$ Auth $\backslash$ Authenti catesUsers;

use

Illuminate $\backslash$ Support Facades $\backslash$ Auth; class LoginController extends Controller

\{

/*

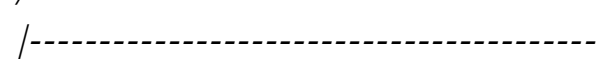

| Login Controller

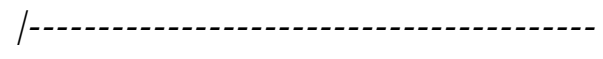

| This controller handles authenticating users for the application and

| redirecting them to your home screen. The controller uses a trait

| to conveniently provide its functionality to your applications.

*/

use AuthenticatesUsers;

/**

* Where to redirect users after login.

*@var string

*/

$/ /$ protected \$redirectTo = RouteServiceProvider::HOME;

/**

* Create a new controller instance.

*@returnvoid

*/

public function __construct()

\{

\$this->middleware('guest')-

>except('logout');

\}

public function redirectTo()

\{

if

>hasRole('admin')) \{
\$this->redirectTo

route('admin.users.index'); return \$this->redirectTo;

\}

else if (Auth::user()-

>hasRole('author')) \{

\$this->redirectTo

route('admin.users.index');

return \$this->redirectTo;

j

else if (Auth::user()-

>hasRole('user')) \{

$\$$ this->redirectTo

route('home'); return \$this->redirectTo;

\} $\}$

Algoritma Kernel.Algoritma ini bertujuan untuk membuat kelas-kelas sesuai dengan objeknya dan disini diperlihatkan kelas-kelas tersebut menjadi singkatan-singkatan route ketika ditempatkan pada halaman dashboard content maupun di home page content seperti "auth, can, checkrole" dan sebagainya. Diberikan sebagai berikut:

protected \$routeMiddleware = [ 'auth' => $\backslash$ App $\backslash$ Http $\backslash$ Middleware $\backslash$ Authenticate:::cl ass, 'auth.basic' => Vlluminate $\backslash$ Auth $\backslash$ Middleware $\backslash$ Authentic ateWithBasicAuth::class, 'bindings' => Vlluminate $\backslash$ Routing $\backslash$ Middleware $\backslash$ Substit uteBindings::class, 'cache.headers' => Vlluminate $Y$ Http $\backslash$ Middleware $\backslash$ SetCache Headers::class, 'can' =>

Vlluminate $\backslash$ Auth\Middleware $\backslash$ Authorize: :class, 'guest' => $\backslash$ App $\backslash H t t p \backslash$ Middleware $\backslash$ RedirectIfAuthen ticated::class, 
'password.confirm' =>

Vlluminate $\backslash$ Auth $\backslash$ Middleware $\backslash$ RequireP assword::class, 'signed' $=>$

Vlluminate $\backslash$ Routing $\backslash$ Middleware $\backslash$ Validat eSignature::class,

$$
\text { 'throttle' }
$$$$
=>
$$

Vlluminate $\backslash$ Routing $\backslash$ Middleware $\backslash$ Throttl eRequests::class, 'verified' $=>$

Vlluminate $\backslash$ Auth $\backslash$ Middleware EnsureEm ailIsVerified::class, 'checkRole' $=>$ $\backslash$ App \Http\Middleware $\backslash$ CheckRole::clas $s$, ];

\section{Perancangan Content Management System}

Algoritma Template Content Management System (CMS). Algoritma ini bertujuan untuk memberikan ruang bagi template yang akan diganti-ganti dengan mudah, hanya dengan sekali klik perubahan pada database nya. Hal ini sangat penting jika template dirasa terlalu membosankan untuk tampil dalam jangka waktu yang lama. Template hanya bisa diakses setelah terverifikasi sebagai pengakses yang tervalidasi untuk home page content. Untuk penelitian ini template cukup diberikan sebanyak 5 (lima) template. Diberikan sebagai berikut : @foreach (\$template as $\$ t$ ) @if

$>$ template $==={ }^{\prime}$ Pertama ${ }^{\prime}$ ) @yield('templatePertama') @elseif

$>$ template $==={ }^{\prime K e d u a '}$ )

@yield('templateKedua')

$$
\text { @elseif }
$$

>template $==={ }^{\prime}$ Ketiga' $\left.{ }^{\prime}\right)$

@yield('templateKetiga')

@elseif

>template $===$ 'Keempat $^{\prime}$ )

@yield('templateKeempat')

\author{
@elseif \\ $>$ template $==={ }^{\prime}$ Kelima' $)$ \\ $(\$ t-$ \\ @yield('templateKelima')

$$
\begin{aligned}
& \text { @endif } \\
& \text { @endforeach }
\end{aligned}
$$ \\ @extends('welcome') \\ @ section('templatePertama') \\ @yield('template1',
}

View::make('tampilwebsite.template1.te mplate 1'))

@endsection

@ section('templateKedua')

@yield('template2',

View::make('tampilwebsite.templat

e2.template2'))

@endsection

@ section('templateKetiga')

@yield('template3',

View::make('tampilwebsite.template3.te mplate3'))

@endsection

@ section('templateKeempat')

@yield('template4',

View::make('tampilwebsite.templat e4.template4'))

@endsection

@ section('templateKelima')

@yield('template5',

View::make('tampilwebsite.template5.te mplate5'))

@endsection

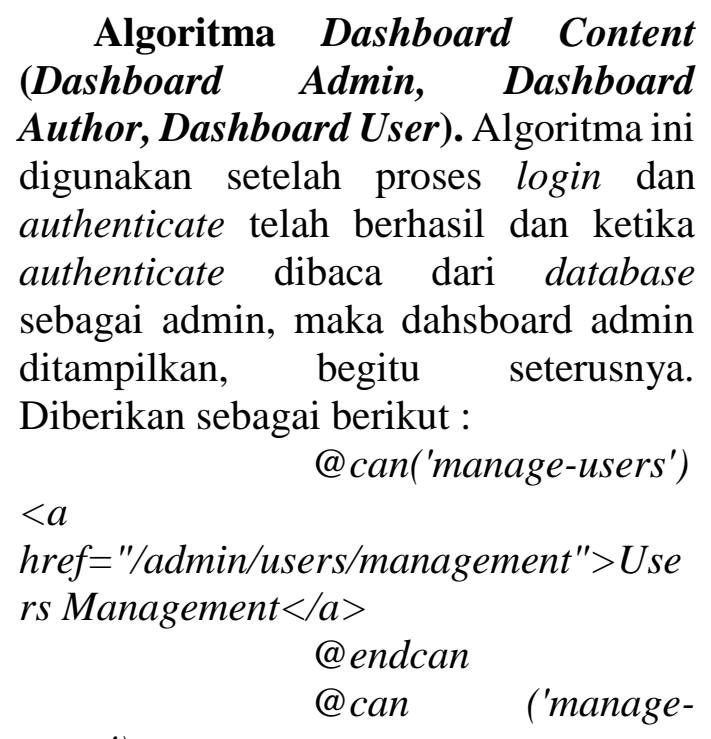

users' $^{\prime}$ 
$<a$

href $="\{$ route('admin.users.managemen

$\left.\left.\left.t^{\prime}\right)\right\}\right\}^{\prime \prime}>$ User Management $\langle/ a\rangle$ @endcan

@yield('konten_dashboard')

@yield('konten_management')

@yield('konten_editUsers')

@yield('konten_profile')

@yield('konten_berita')

@yield('konten_editNews')

@yield('konten_tambahNews')

@yield('konten_template')

Algoritma Home Page Content. Algoritma ini bertujuan untuk membuat opsi pada halaman depan atau home page, baik tanpa login maupun dengan login yang terverifikasi admin, author maupun user, hal ini berguna bagi pengguna untuk memilih masuk sistem atau hanya sebagai tamu di luar sistem saja, disini digunakan algoritma "can" yang telah disebutkan di algoritma kernel untuk mengidentifikasikan si pengguna dalam mengakses halaman depan (home page)

\section{@guest}

@if

(Route::has('register'))

$$
\text { @endif }
$$$$
\text { @else }
$$

$\langle$ li class="nav-item dropdown" > $<$ a href="\#"> \{f Auth::user()-

$>$ name $\}\}\langle$ span class ="caret" $\rangle$

$\langle/ a\rangle$

$\langle$ div $\rangle$

$<$ a href $="\{\{$ route('logout') $\}\} "$

onclick="event.preventDefault();

document.getElementById('logout-

form').submit();">

$\{1$ _ ('Logout')

3\}

$\langle/ a>$

users')

$<a$

href $="\{\{$ route('admin.users.index' $)\}\} ">$

User Management $\langle/ a>$

@endcan

$<$ form action $="$ " $\{$ route $($ 'logout' $)$

\} $\}^{\prime \prime}$ method="POST">

@ csrf

$\langle/$ form $\rangle$

$\langle/$ div $\rangle$

$\langle/ l i\rangle$

@endguest

\section{Hasil Sistem Login yang Baru}

Berikut hasil dari algoritma yang telah disusun ke dalam rupa aplikasi berbasiskan website beserta dengan pengujiannya:

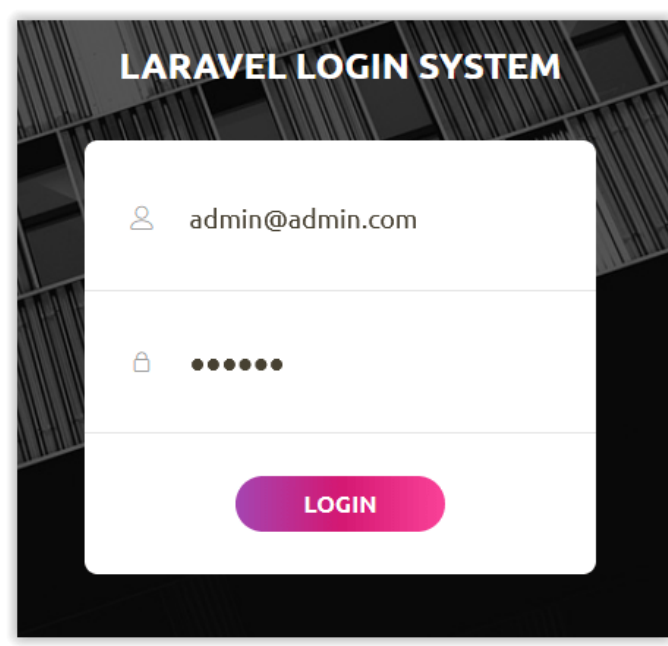

Gambar 9. Tampilan Login Admin 


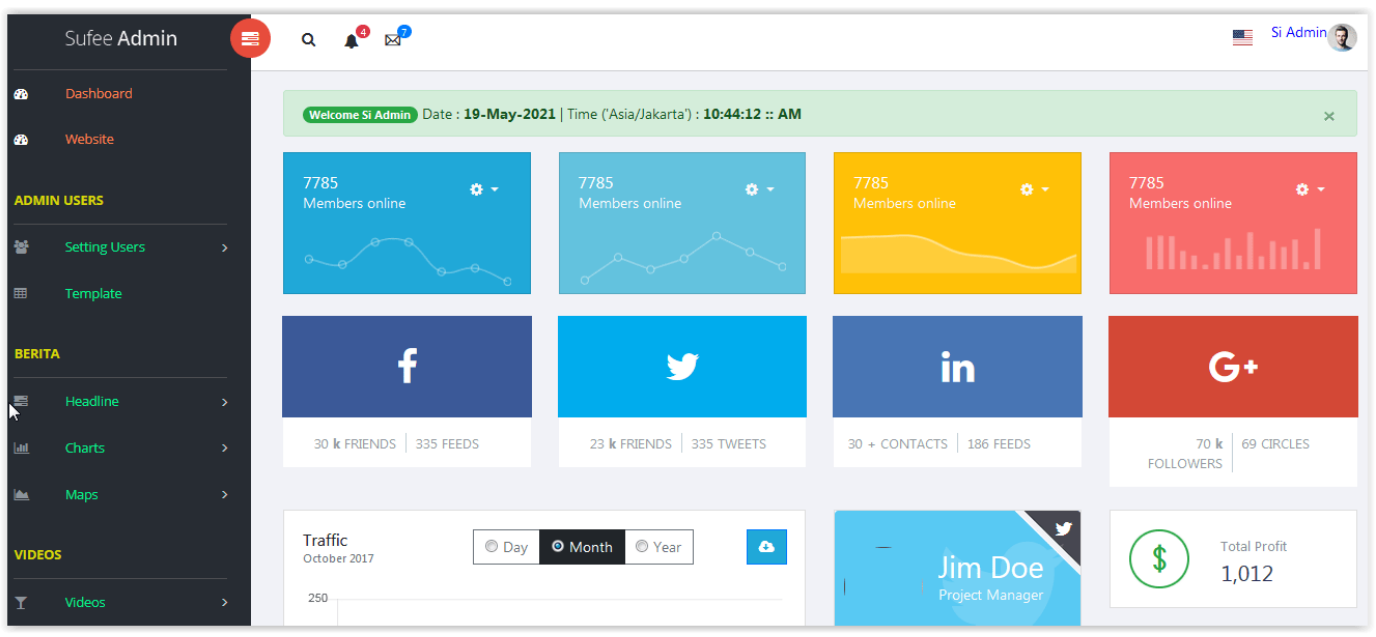

Gambar 10. Login dengan Akun Admin

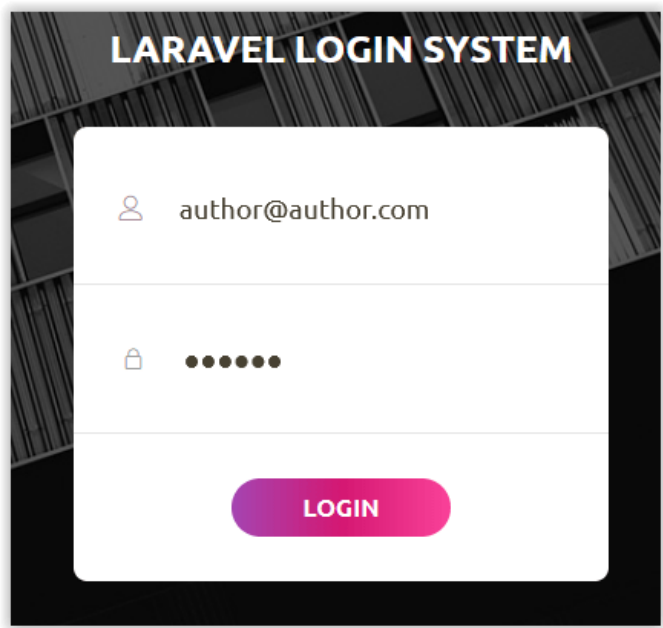

Gambar 11. Tampilan Login Author

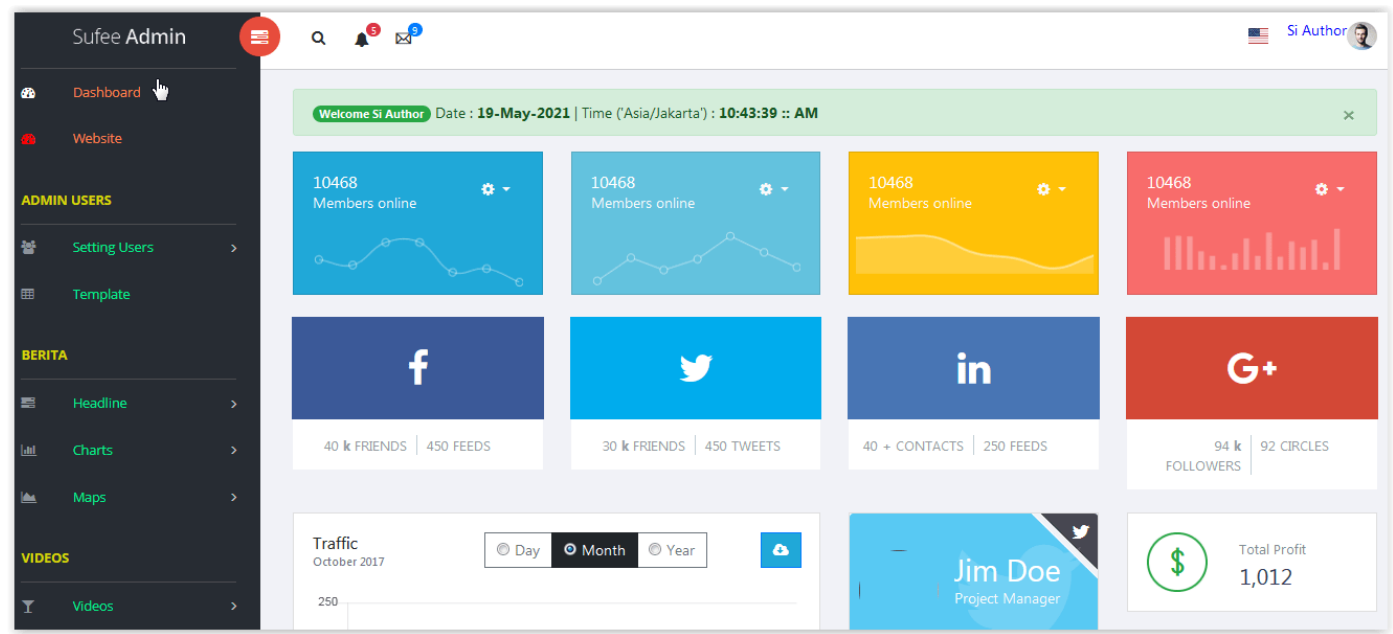

Gambar 12. Login dengan Akun Author 


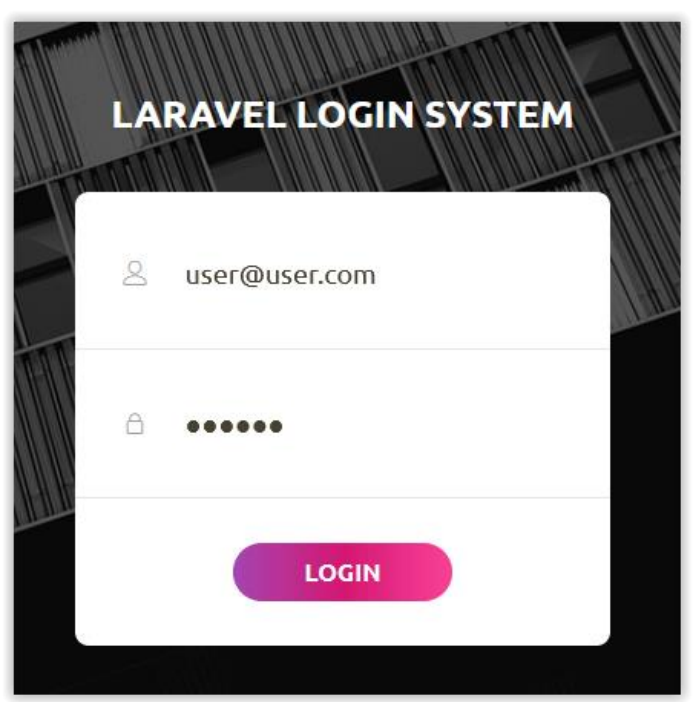

Gambar 13. Tampilan Login User

Gambar 14. Login dengan Akun User

Tabel 3. Pengujian Sistem Login yang Baru

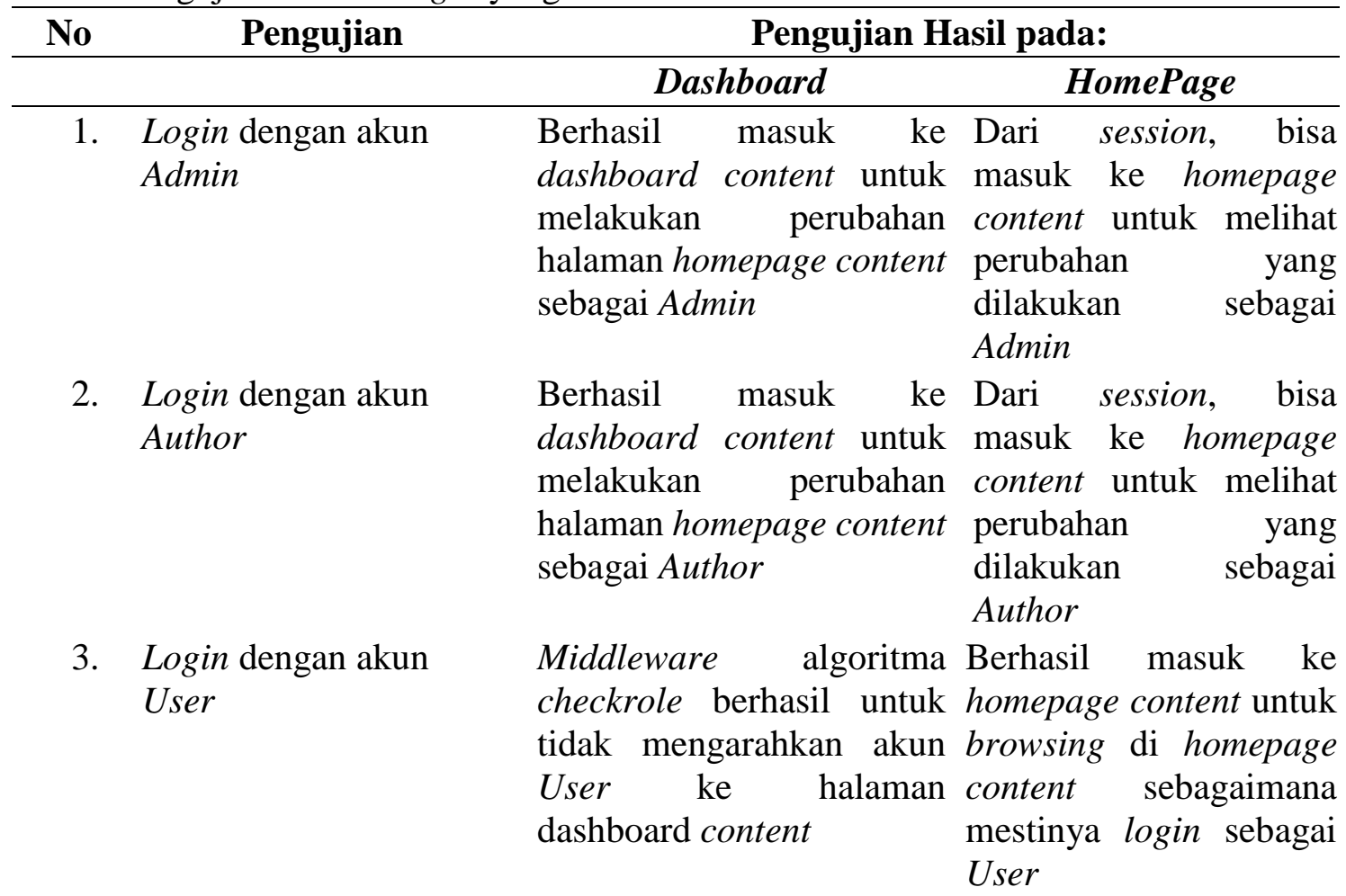


4. Tanpa login (quest)

5. Login merusak dengan SQL Injectionseperti : admin'or $1=1 \#$ or $1=1 \#$ 'or"a"="a"\# admin' OR '1'='1 admin ' or ' $x$ '='x admin 'or"a"="a"\#

6. Masuk awalnya sebagai User, lalu mengkopi link masuk sebagai Author dengan akun User

7. Masuk awalnya sebagai Author, lalu mengkopi link masuk sebagai Admin dengan akun Author
Middleware algoritma Bisa langsung akses checkrole berhasil untuk homepage tanpa login tidak mengarahkan akun sebagaimana mestinya Quest ke halaman Quest dashboard content

Middleware Algoritma Middleware Algoritma SHA-3 berhasil untuk SHA berhasil untuk memblokir SQL injection memblokir SQL untuk masuk ke dashboard injection untuk masuk content di homepagecontent

Tidak berhasil masuk di Middleware memang dashboard content. memberikan akses Muncul pesan proteksi dari sebagai user untuk middleware algoritma masuk di homepage checkrole dengan pesan contentsebagai validasi "forbidden access 403This action is user yang semestinya unauthorized"

Berhasil masuk di Middleware algoritma dashboard content. Namun dashboard content tetap sebagai Author dan hanya membatasi di dibatasi gerakannya untuk dashboard content saja mengubah level pengguna dan masih memberikan karena ada algoritma akses sebagai Author dashboard content yang untuk masuk di membatasi dengan homepage content can:manage untuk Author sebagai validasi Author mengubah menu-menu yang semestinya yang tidak diizinkan

\section{KESIMPULAN DAN SARAN}

Adapun kesimpulan yang di dapatkan dalam penelitian ini yaitu :

1. Penggunaan login authentication bawaan dari laravel belum mencukupi untuk keamanan data dalam akses serta belum memiliki sistem Multi Level Akses (MLA) untuk penggunaan tingkat lanjut
2. Penggunaan dan pengujianAlgoritma Middleware Checking Access System, yang meliputi algoritma : Authentication, Checkrole, VerifyCsrfToken telah mampu untuk mempetakan pengguna yang akan login dengan sekali akses untuk : akun login, session, validasi authentication, level login, serta 
3. memungkinkan proses ini untuk membatalkan akses jika terindikasi SQL injection.

4. Penggunaan dan pengujian Algoritma Middleware Checkrole telah berhasil untuk membatasi masuknya akun level bawah dengan mengkopikan saja link akun level di atasnya dengan pesan "forbidden access 403 This action is unauthorized".

5. Dilengkapi dengan keberhasilan pengujian Algoritma Dashboard Content yang membatasi akses level Author untuk masuk dan mengelola menu-menu pada level admin

Adapun saran yang diperlukan untuk pengembangan sistem login ke depannya adalah diperlukannya tambahan sistem akses database tipuan atau pancingan untuk akses merusak SQL injection agar kalaupun SQL injection mampu untuk meretas sistem ini, maka dia akan diarahkan ke database tipuan dan terkunci session access disana dan tidak bisa untuk kembali mengakses sistem.

\section{DAFTAR PUSTAKA}

Dharmawan, E. A., Yudaningtyas, E., \& Sarosa, M. (2013). Perlindungan Web pada Login Sistem Menggunakan Algoritma Rijndael. Eeccis, 7(1), 77-84.

Handika, I. G., \& Purbasari, A. (2018).

Pemanfaatan Framework Laravel Dalam Pembangunan Aplikasi ETravel Berbasis Website. 8-9.

Kurniawan, F., Kusyanti, A., \& Nurwarsito, H. (2017). Analisis dan Implementasi Algoritma SHA-1 dan SHA-3 pada Sistem Autentikasi Garuda Training Cost. 1(9), 803812.

Santoso, G. B., Sinaga, T. M., \& Zuhdi,
A. (2021). MVC Implementation In Laravel Framework For Development Web-Based ECommerce Applications. Intelmatics, 1(1), 37-42. https://doi.org/10.25105/itm.v1i1.7 867

Setiawan, Y., Sajati, H., \& Sudibya, B. (2013). Perancangan Keamanan Sistem Menggunakan Algoritma Honeypot Pada Aplikasi Krs Online (Studi Kasus: Sekolah Tinggi Teknologi Adisutjipto). Compiler, 2(2), 143-148. https://doi.org/10.28989/compiler. v2i2.56 
